\title{
An estimation of the function of postal mails demand and awareness of response by the postal service customers against mails' price hikes
}

\author{
Seid Hamed Hosseini \\ The Kurdistan's General Post Office, Kurdistan, Iran \\ E-mail address: Hamed.hosseini@post.ir
}

\begin{abstract}
The aim of the research is an estimation of the function of postal mails demand and awareness of response by the postal service customers against mails' price hikes. During the period under study, statistics and information related to mails issued annually at the national level were examined, collected and then using the statistical methods as well as regressions, the functions in question were estimated. In this research, the documentary method was applied to identify and collect statistical data and then through direct reference to the records of the statistics of the post companies, telecommunication company, department of management and planning, as well as the central banks, data needed were collected. Using the regression models, the estimated function of the linear demand was carried out by way of minimal normal squares (ols) and minimal non linear squares (nls). Findings revealed that the postal service demand is positively and directly related with the population. Results, also, suggested that the postal service demand is a function of the national income and is found to be directly and positively correlated with it. Given the demographic natural growth and increased demand for the postal services as a result of the population growth, facilities should too, increase.
\end{abstract}

Keywords: Demand function; Postal mails; Price elasticity; Post

\section{INTRODUCTION}

Post in modern life, has a vital and an undeniable role. Post is thought to be an agent and a fundamental pivot in the cultural and socio-economic expansion. Post has substantial implications since it facilitates the commercial exchange process, advertisements, payments, financial deposits, and is highly active in all production phases as well as in establishing a specialized and cheap communication by facilitating the economic activities for all the economic sectors through the socio-economic labor division. Post can be effective in the society once there is a need for postal services. Postal services vary and so do the prices. Furthermore, the way clients respond to price changes vary also.

Mails that in their shipments, there is a substitute for the post, have higher price elasticity and mails with no such properties, have lower price elasticity. Post is taken from the Sanskrit word (Postas) meaning fixed. This term has changed to post in Latin, referring to stations where spare horses were kept for the traveling passengers. This term became the word post as we know it. Another theory maintains that post is of Persian origin whose original word was (posht) that the appellation is letters sent as travelers left. Given this the Ottoman Turks used 
to call post as (poshta) and a great part of Turkish word is of Persian origin. Hence, it can be said with certainty that the Turkish (poshta) is taken from the Persian (posht). (Pezman, 1947).

Post is a widespread general network that accepts and prepares to transport and distribute messages or packets sent from one point to another by most appropriate prices and secure speed. Also, post, as a specialized communication network enters in the social labor division system, in order that production is enhanced, and socio-economic communication costs are diminished (Tayari, 1991).

A need for a means for exchange was applied from the beginning of the social human life followed by various facilities in the human's life environment. Various tools were applied for exchanging thoughts, information and goods as time lapsed and through the process of the social development. In this regard, communication that post is one of its branches was formed. Production requires exchange so that produced goods are provided to the consumers. Exchange, in turn, needs communication tools. In this regard, as a communication tool, post plays the intermediary role between the producer and consumer. Because the advent of services and goods are generated by the social human needs, it can be said, postal services have been formed based on the needs and properties governing the human societies. The Chappari (letter carrier) post had the role of transferring the news and social situation among the rulers and emirs, thereby, acting as an exchange tool. This sort of post was in the monopoly of the government for obtaining information concerning the political and military issues. In industrial societies where the production of goods and services are done in bulk, the necessity to rapidly and uninterruptedly displace these products, has led to the fact that the postal communication becomes a means for transferring documents, information and goods. Thus, the need to the postal services formed based on the properties governing on the societies is created differently and under different function in societies, thereby, it has grown and been applied.

\section{THE ISLAMIC REPUBLIC OF IRAN POST COMPANY}

In order to organize, plan, fulfill sources, guide, supervise and control for offering appropriate postal services based on speed, accuracy and security and following the general policies based on the self sufficiency of the service entities, it was stated that post as a state corporation conducts the postal service affairs, in order that it collects the potential and existing mails and performs its own main role as an agent of development through better services following cultural, social and economic developments. Thus, the law pertaining to the formation of the post company was approved by the Islamic council parliament in 1987, October $7^{\text {th }}$. The law was also approved by the guardian council in the same year. One of the definitions of demand is the ability and inclination of the people to use a good or service at a given time. The ability of people to use goods and services is dependant on their income level and prices of goods and services in question. While their inclination depends on the people's needs to have those goods and services as well as their quality. Thus, there is a demand for a good or service once its price matches the income level of the user and also the quality be in such a way that draws the satisfaction of the clients. To understand the ability level and people's tendency to use a good or service, factors affecting the demand should be analyzed. These factors are price, income and other qualitative and quantitative factors affecting demand. Generally speaking, in post, in order that facilities required by clients are created, some of the services are offered differently, including transferring mails in the forms of normal, custommade, insurance, Express, reception from the sender's headquarter as well as Restant post. 


\section{1. Normal mails}

Mails whose senders apply no special request for their transference and post does not act specifically except for the very normal post process.

\section{2. Custom-made mails}

This type involves mails whose senders apply for a receipt from the post company while delivering them. The post company gives an official receipt to their senders and receives signatures from the recipients while delivering them. Post is charged with custom-made mails and is obliged to pay compensation in case these mails are lost or disappeared.

\section{3. Insured mails}

In case the client demands, the postal mails are insured by the post based on the said price of their contents by the sender. The postal operations carried out on these mails resemble those of custom-made mails and in addition in case these mails are lost or disappeared, the post company will be bound to pay compensation equivalent with the said amount in return for the content of the mails. Any valuable thing, cash or any thing considered valuable in the eye of the sender, will be transferred to the destination with the said value.

\section{4. Reception from the sender's head quarter}

Senders could without leaving their place of residence or office telephone the post office, demanding it to send its carriers to receive their mails and to send them to the required places.

\section{5. Restant post}

Should mail recipients have no definite address could through referring to the postal unit of their place of residence demand from the said unit to receive postal mails they get at the said office. This service is of help for passengers, traders, tourists and people having no definite and fixed address. Selecting an appropriate utility function is of high significance. because, limited functions are know in this regard, this will make the demand function inference become difficult.

Function characteristics are functions of this selection themselves. Furthermore, the demand function inferred could be so complicated whose statistical estimation becomes impossible (Saeednia, 2001).

Because postal services are diverse and prices differ, the response by clients against service price changes will differ. Because, to send some of the mails like postal packets clients have to act through the post based on the law. For some other services such as trust funds, there is no such obligation. Mails that in their shipments, there is a substitute for the post, have higher price elasticity and mails with no such properties, have lower price elasticity. Thus, if the price of postal packets and trust funds increase in the same way, it is expected that demand reduction for postal trust funds to be much more than that for the packet demands. The aim of the research is an estimation of the function of postal mails demand and awareness of response by the postal service customers against mails' price hikes. (Hosseini, 2007).

The postal service offering is post specific. The monopoly seller has no supply curve (Ferguson, 1991). The final cost curve (MC) has not remained constant along with the service sale costs in recent years. Hence the equilibrium points are obtained by the collision of these different prices with the demand curve of the consumers. In other words, the service prices are determined in the form of endogenous by the post, not by service demand and supply curves. 
Here consumers will react through their own demand against each price target announced for the postal services.

Thus, the geometric place obtained will specify the demand curve not another function. Now that theoretical issues are elucidated, we deal with the formulation of the demand model. The postal service function is as follows:

$$
\mathrm{Q}_{\mathrm{d}}=\mathrm{F}\left(\mathrm{p}_{\mathrm{t}}, \mathrm{Y}_{\mathrm{t}}, \mathrm{N}_{\mathrm{m}}\right)
$$

where, $Q_{d}$ is the number of mails, pt, the consumer's income and $\mathrm{N}_{\mathrm{m}}$ is the number of consumers. The above function can be estimated using the seasonal and yearly statistical information. In each case, it is expected that the coefficient sign of the price be negative.

The impact of a change to the consumer's income on the demand value is direct. If we suppose as constant the other factors, the income estimated coefficient will show this impact (Fergusen, 1991).

The first research was performed in 1993 in which the demand functions of the postal services based on service type (civil normal letters, intercity custom made letters) were estimated. An estimation of demand functions of any products is to determine the factors affecting demand for the postal mails and to predict the postal services in the next years (Hossein, 2006). Findings by Dashtban (2005) revealed that in a year, the gross domestic product and the possibility of disorder as on accuracy index in offering postal services and the number of telephones engaged as a substitute good as well as two virtual war variables and the internet have been utilized. Also, the postal service demand elasticity compared to the picture post numbers sent was reported $0 / 41$.

The elasticity sign being positive suggests that the letters sent through fax require a follow up due to the fact they are of office origin as well as increased number of faxes sent will lead to an increase in the number of postal traffic. In other words, the complementary impacts of this section is more than the substitution impact, showing a complementary relation between the postal traffic and the number of picture post sent. On the other hand, economic factors like economic boom and recession of a country, per capita income of the social economic activities quality like the products being industrial and traditional or the society being consumer will contribute significantly to the demand level for the postal services. Because the economic boom means more production and consumption that could affect positively the demand by both producers and consumers for the postal services. Culture imposed on a country including the consumption. Model of the relationships existing among the people as well as the culture imposed on organizations have a profound effect on the demand level for the mails. Generally, a change to the culture imposed on the society will result in structural changes to the demand level for the mails, thereby affecting the demand level.

\section{METHODOLOGY}

In this study, is has been attempted to estimate the demand function for each of the postal mails and to determine the demand price elasticity of each of these said mails using the regression and existing statistics. In this study, attempts have been exerted to considered the price of the substitute goods for each sort of mails. For example, telephone could be regarded as a competitor for letter, but it cannot compete with the postal trust funds. While the private companies like Tip ax are competing with postal trust funds, they do not compete with postal trust funds due to monopoly. This investigation has refereed to the peoples' response to the 
price hikes of the postal mails and the relationship between the economic and demographic variables at the national level along with the demand level of the postal services has been examined.

More importantly, through obtaining the statistics related to the issued mails of the countries during 1977-2003 from the bureau of the post studies and planning and using the statistical and regression methods as well as Excel and E views software, the function of the services demand has been estimated. It has been tried in this investigation that the price of the substitute goods for each of the mails is considered. The statistical population used is the number of the mails issued annually at the national; level. The statistical population used is the number of the mails issued annually at the national; level includes intra city normal letters, internal custom made letters, intercity normal letters, normal letters sent abroad and custom made letters sent abroad.

\section{FINDINGS}

Table 1. Coefficients of the price elasticity of some of the postal mails in models constructed.

\begin{tabular}{|c|c|c|c|c|}
\hline Mail name & $\begin{array}{c}\text { Coefficient of } \\
\text { price elasticity } \\
\text { in 1992 }\end{array}$ & $\begin{array}{c}\text { Coefficient of } \\
\text { price elasticity } \\
\text { in 1999 }\end{array}$ & $\begin{array}{c}\text { Coefficient of } \\
\text { price elasticity } \\
\text { in 2005 }\end{array}$ & $\begin{array}{c}\text { Coefficient of } \\
\text { price elasticity } \\
\text { in the present } \\
\text { research }\end{array}$ \\
\hline $\begin{array}{c}\text { Intra city } \\
\text { normal letters }\end{array}$ & $-0 / 71$ & $-0 / 3$ & $-0 / 45$ & $-0 / 98$ \\
\hline $\begin{array}{c}\text { Civil custom } \\
\text { made letters }\end{array}$ & $-1 / 2$ & $-0 / 31$ & $-1 / 3$ & $-1 / 36$ \\
\hline $\begin{array}{c}\text { Intercity normal } \\
\text { letters }\end{array}$ & $-0 / 68$ & $-0 / 2$ & $-0 / 29$ & $-0 / 76$ \\
\hline $\begin{array}{c}\text { Intercity } \\
\text { custom made } \\
\text { letters }\end{array}$ & $-0 / 34$ & $-0 / 51$ & $-0 / 61$ & -0.23 \\
\hline $\begin{array}{c}\text { All of the } \\
\text { normal and } \\
\text { custom made } \\
\text { letters inside } \\
\text { the country }\end{array}$ & $-1 / 23$ & - & $-1 / 87$ \\
\hline $\begin{array}{c}\text { Normal letters } \\
\text { sent abroad }\end{array}$ & $-0 / 13$ & $-0 / 41$ & $-0 / 14$ & $-0 / 60$ \\
\hline $\begin{array}{c}\text { Custom made } \\
\text { letters sent } \\
\text { inside and } \\
\text { abroad }\end{array}$ & $-0 / 38$ & $-0 / 42$ & $-0 / 016$ & -0.51 \\
\hline $\begin{array}{c}\text { All of the } \\
\text { normal and } \\
\text { custom made } \\
\text { letters sent } \\
\text { inside and } \\
\text { abroad }\end{array}$ & $-1 / 30$ & - & & -25 \\
\hline
\end{tabular}




\begin{tabular}{|c|c|c|c|c|}
\hline Insured mails & $-0 / 88$ & - & - & - \\
\hline $\begin{array}{c}\text { Internal trust } \\
\text { funds }\end{array}$ & $-0 / 65$ & - & - & - \\
\hline Press & $-0 / 06$ & $-0 / 24$ & - & - \\
\hline
\end{tabular}

Results of the table indicated that price in all the models has a required sign. The coefficient of the price elasticity in all the models for the postal mails excepting the intra city custom made letters is lower than 1. Recent letters have a coefficient of the price elasticity of less than one. This difference could derive form the difference in the period under study as well as the conflicts in the statistics under investigation, while the price variable in the said model is not statistically approved.

Table 2. Coefficient of price elasticity of some of the postal mails.

\begin{tabular}{|c|c|}
\hline Name of mail & Coefficient of price elasticity \\
\hline Intra city normal letters & $-0 / 98$ \\
\hline Intra city custom made letters & $-1 / 36$ \\
\hline Intercity normal letters & $-0 / 76$ \\
\hline Intercity custom made letters & -0.23 \\
\hline $\begin{array}{c}\text { All the normal and custom made letters } \\
\text { inside the country }\end{array}$ & $-1 / 87$ \\
\hline $\begin{array}{c}\text { Normal letters sent abroad } \\
\text { Custom made letters sent abroad }\end{array}$ & $-0 / 60$ \\
\hline $\begin{array}{c}\text { All the normal and custom made letters } \\
\text { sent inside and abroad }\end{array}$ & $-0 / 51$ \\
\hline
\end{tabular}

Results of the table indicate that despite the fact that the coefficient of the price elasticity of intercity custom made letters is lower than that of the intercity normal letters.

\section{DISCUSSION AND CONCLUSION}

The aim of the present research was to estimate the demand function of the postal mails and the awareness of the clients' responses against the increase of the mails price where the results indicated that the coefficient of the price elasticity of the normal intra city letters is greater than that of the normal intercity letters while the coefficient of the price elasticity of the normal intercity letters is greater than letters sent abroad. This issue is due to the fact that the more the substitute communication tools will be used, the more the price elasticity will be. 
Thus, the intra city letters elasticity is greater than that of the intercity while the intercity letters elasticity is greater than letters sent abroad. In each case, the function estimated for all the internal letters inside the country as well as the overall internal letters and those sent abroad, the coefficient of the price elasticity obtained is more than the coefficient of the elasticity of the elements price, each of the mails separately.

This implies that one has to be careful in absolute acceptance of the obtained elasticity coefficients, due to the shortened period under study as well as limited number of the change times in the price of the postal mails. Because, as the number of observations increase in general models, the price fluctuations will show their own effects to a great extent. In other words, it is possible, with the increase in the period under study and the increase in the number of the change times in the mails prices, the obtained elasticity coefficients for each of the mails are more than the coefficients obtained in this investigation.

The reason is that the custom made letters are generally office letters. Regarding the intra city letters, as the price increases, large departments and offices will prefer to employ people as mail carriers instead of the post networks so that they can distribute intra city letters by them and that's why, the coefficient of the price elasticity of the intra city custom made letters is greater than that of the intra city normal letters, these entities cannot transfer their intercity letters by themselves and they have no choice but to use the post network to transfer those letters.

Concerning the letters sent abroad, it can be said that the ratio of the demand by the organizations for transferring letters abroad is lower than that by the firms and users. Generally speaking, the elasticity of the consumers and the private sector is more than that of the public offices and organizations. Thus, the elasticity of the normal letters sent abroad is more than the foreign custom made letters (Center for the post research, 1994).

Given the fact that the demand for the postal mails is the result of the demand by the consumers, producers and distributers, each variable that affects for all or each of them will be effective in demand for the postal mails. It was clarified during the performed studies, that in addition to price, population variables, income population with the national literacy, the service sector contributes to the national gross production and the degree to which telephone is used are effective on the demand for the postal mails. Increased population, due to the fact that they need trade, artistic and cultural exchanges as well as the social relationships, has resulted in increased demand for communication and as a result demand for the postal mails which is one of the communication ways is increased. Income increase means an increased purchasing power by the consumer and the increased economic activities, i.e. increased goods and service production. This wills inn each case, results in the demand for the postal mails. An increase in the number of literacy level will facilitate correspondence and on the other hand, literacy itself, follows such needs as need to access for the educational and cultural products, office correspondence as well as correspondence with information centers where these factors themselves affect the demand for the postal mails. On the other hand, the correspondence of the literate people because of the said reasons are of high value and hence, requiring high quality services.

This will again result in the people's turning to high quality mails where those factor has a negative impact on mails that have lower quality. Service sector activities are in such a way that follows the transference of a great number of goods and different correspondence like bank services, insurance organizations, and educational and commercial entities. Thus, as the share of the services increase in the national; gross production, demand for communication that post is part of it will increase. Telephone is a related good with the postal letters, hence, the 
information related to this communication tool of the function demand has been used for the postal letters.

Studies conducted suggest that telephone can have two different impacts on demand for the postal letters where one of them is the substitution effect and the other is complementary effect. In other words, telephone conversations could substitute the postal mails and on the other hand, these conversations could follow the postal letters. What actually determines the role of the telephone as a substitute or complementary good concerning the estimated function for each mail, is the net of the these two impacts on demand for the said mail.

Concerning the demand function for the postal mails, the real price, i.e. the price ratio for these mails to the index of goods costs and urban consumption services (cpi) has been applied. The reason why the real price is used instead of the nominal price is that during the first years under study, the price of these mails have remained constant while the society has faced with severe inflation and in fact the price of these services compared to the other goods and services offered has been on the decline side.

\section{Limitations of the research}

Due to the fact that the role and value of the economic activities in the society has been intangible, collaboration in the area of statistics collection has been much too low and limited. Also, the absence of the research records and the ordered and concentrated statistical system, access to the required data and statistics was a challenge. More importantly, because of the lack of the statistics and information required, the new postal services were not examined and this has been one of the limitations of the research.

\section{Recommendations}

1. The period under study was a period full of ups and downs, because in this period important events such as revolution and war happened. These events had a substantial impact on the social activities as well as communication and demand for the postal mails. Even, it is possible that these events have to some degree overshadowed the role of the price on demand

2. Price changes in the period under study were quite limited where this will have a negative impact on the accuracy of the results

3. Due ton the fact that in the linear demand functions, the price elasticity will not remain constant along the demand function, It is possible that the price increase moves us to the part of the demand function where it has the price elasticity of more than one. In this case, price increase will not result in income increase.

Thus, although the results obtained explain that effect of the price changes of the postal services on demand for these services, considering the above mentioned items should be taken care of with regards to the results. Also, the absence of the research records and the ordered and concentrated statistical system, access to the required data and statistics was a challenge. More importantly, because of the lack of the statistics and information required, the new postal services were not examined and this has been one of the limitations of the research. 


\section{References}

[1] Pezman H. (1947). History of post and telegraph and telephone, Tehran: Post Publications.

[2] Saeednia, Esmaeel (2001). Estimating the demand function for the drinking water and its pricing policies, M.A. thesis, Tarbyat Modares University, Tehran.

[3] Fergusen Charles (1990). The theory of microeconomics, Tehran, Nashr Center.

[4] Dashtban Manije (2005). Estimating the functions of post supply and demand, Doctoral thesis, Shahid Beheshti University, Tehran.

[5] Center for post research (1993). Estimating the demand function of the Iranian postal services, Post research center, Tehran.

[6] Hosseini Seidhamed (2007). Estimating the demand function of the Iranian postal mails, M.A thesis, Islamic Azad university, Tehran Markaz branch.

[7] Tayari Jafar (1991). Marketing in post, Tehran: Post training center publications. 